\title{
A liderança das escolas em três regiões portuguesas: uma visão a partir da avaliação externa* $^{*}$
}

\author{
Helena Quintas \& José Alberto Mendonça Gonçalves \\ Universidade do Algarve, Portugal
}

\begin{abstract}
Resumo
A liderança escolar tem efeitos significativos na aprendizagem, desenvolvimento e sucesso académico dos alunos e na qualidade das organizações educativas, pelo que das suas práticas depende, em grande medida, a eficácia da ação da escola. Foi tendo estes pressupostos por referentes que desenvolvemos o estudo a que este artigo se reporta. Nele procuramos caracterizar a liderança das escolas e agrupamentos de escolas de três regiões portuguesas (Algarve, Alentejo e Lisboa e Vale do Tejo), com base na análise de conteúdo efetuada aos relatórios de avaliação externa produzidos pelas equipas da Inspeção-Geral da Educação nos anos letivos de 2006/2007, 2007/2008 e 2008/20091. O estudo teve como objetivos compreender como as organizações educativas põem em prática a sua visão de escola e como implementam a partilha e a circulação da informação para darem consecução a metas e propósitos que estabeleceram, dando assim corpo à linha hierárquica de exercício do poder. A análise dos dados agora efetuada permitiu-nos traçar um "perfil" das lideranças das escolas e agrupamentos de escolas avaliados, embora consideremos que os seus resultados não possam ser extrapolados, dados os limites da redação dos relatórios de avaliação externa e o facto de estes serem produzidos por equipas diferentes de região para região e nas próprias regiões.
\end{abstract}

Palavras-chave

Avaliação externa das escolas; Relatórios de avaliação; Liderança; Exercício da liderança

\section{Introdução}

A avaliação dos estabelecimentos de Educação Pré-Escolar e dos do Ensinos Básico e Secundário foi instituída pela Lei n. ${ }^{\circ}$ 31/2002, de 20 de 
dezembro, e é configurada por um sistema que engloba dois processos complementares: a autoavaliação e a avaliação externa, que teve uma fase de experimentação em $2006^{2}$. A autoavaliação é desenvolvida pela própria organização educativa, que deverá produzir "um discurso constituído por juízos de valor que relacionam um referido (algo que é observado, registado, apreendido acerca do objeto avaliado) e um referente (algo que se apresenta como um ideal ou uma norma)" (Figari, 1996). A avaliação externa, que foi atribuída à Inspeção-Geral da Educação (IGE), conta com a colaboração de peritos externos pertencentes a instituições de Ensino Superior e traduz-se na produção de um relatório que tem por referentes vários domínios do desempenho das escolas, a análise documental do relatório de avaliação interna das escolas e entrevistas em painel realizadas a um conjunto muito diverso de atores. $O$ relatório visa devolver à escola avaliada uma imagem que a leve a definir os aspetos em que deve e quer melhorar.

Num ciclo de quatro anos (entre 2006 e 2010), foram avaliadas todas as escolas e agrupamentos de escolas do continente e, a partir de 2010, foi reiniciado um segundo ciclo de avaliação externa. No primeiro ciclo de avaliação, os domínios de análise eram cinco (resultados; prestação de serviço educativo; organização e gestão escolar; liderança; capacidade de auto-regulação e melhoria), cada um deles desdobrando-se num número variável de fatores, e no segundo ciclo, atualmente em curso, o referencial compreende três domínios (resultados; prestação do serviço educativo; liderança e gestão), igualmente desdobrados em diversos fatores.

Contextualizado no projeto de investigação em que participámos ${ }^{3}$, o presente estudo circunscreve-se à liderança que é desenvolvida nas escolas (um dos domínios considerados), a partir da análise dos relatórios de avaliação externa. Para o efeito, foram tomadas como objeto de análise, exclusivamente, três regiões portuguesas (Algarve, Alentejo e Lisboa e Vale do Tejo), seleção que se prendeu com a preocupação de contemplar territórios com características distintas. O estudo tem como objetivos compreender como as organizações educativas põem em prática a sua visão de escola e como implementam a partilha e a circulação da informação para darem consecução a metas e propósito que estabeleceram, dando assim corpo à linha hierárquica de exercício do poder. 
Em termos metodológicos, a opção por nos centrarmos na análise dos relatórios de avaliação externa constituiu uma via desafiante para a investigação, na medida em que se parte de um registo realizado pelas equipas de avaliação a partir da informação disponibilizada pelas escolas. Se, por um lado, esta circunstância pode ser encarada como uma limitação, na medida em que é uma informação mediada pelas representações dos agentes que avaliam, por outro, estas tornam-se, em si, objeto de análise. Trata-se, assim, de ter presente que estamos perante uma construção social, o que acontece, na realidade, mesmo quando se trata de fontes primárias. Importa, ainda, acrescentar que o facto de se propor uma análise a partir dos relatórios de avaliação externa permite, de igual modo, constituir-se como uma base de análise de documentos que, numa primeira leitura, têm outros objetivos.

A avaliação externa das escolas tem, certamente, contribuído para uma reflexão acerca das condições organizacionais indispensáveis à promoção do sucesso escolar, e o presente estudo integra-se neste propósito.

\section{Avaliação e liderança das escolas}

\subsection{A avaliação}

A avaliação organizacional no campo educativo pode assumir uma pluralidade de formatos e uma diversidade de respostas e engloba a avaliação interna e a avaliação externa das escolas. Estas modalidades avaliativas distinguem-se nos propósitos que perseguem e nos protagonistas que as efetivam, devendo, contudo, existir uma complementaridade entre ambas que concorra para o desenvolvimento e para a melhoria da organização escolar (Alaiz, 2004; Afonso, 2000; Azevedo, 2002, 2007; McNamara \& O'Hara, 2008; Sá, 2009; Simões, 2007).

A avaliação externa tem como principal função a prestação de contas, no sentido de devolver um balanço sobre a qualidade das escolas, da educação e do ensino que proporcionam, tendo em vista a sua melhoria. Nas palavras de Janssens e Van Amselsvoort (2008), a avaliação externa assume uma dupla função, accountability e improvement, enquanto a avaliação interna "é um mecanismo crucial para a aquisição de qualquer tipo de desenvolvimento da escola" (McBeath, 1999, p. 40). 
O conceito de empowerment (MacBeath, 1999) é frequentemente utilizado para ilustrar o que se julga ser o objetivo último da avaliação das organizações educativas, entendimento que vem reforçar o pressuposto da autonomia que as escolas têm vindo a reclamar (Afonso, 2000; Barroso, 2004). Em muitos países, os processos de avaliação respondem a esta realidade, funcionando como instrumentos de monitorização externa e interna de práticas que as escolas desenvolvem no exercício da sua autonomia (Schildkamp, 2007).

No espaço europeu, sobretudo nos países com uma experiência mais consolidada na avaliação das escolas, como é o caso da Escócia, da Inglaterra e da Holanda, a avaliação externa é da responsabilidade dos serviços da inspeção educativa. Esta prática tem contribuído para a interiorização de que a avaliação das escolas é uma matéria da responsabilidade de uma entidade externa e, consequentemente, tem dificultado processos que coloquem a avaliação como uma tarefa da responsabilidade da própria escola e dos seus atores (McNamara \& O'Hara, 2005).

O longo caminho que tem vindo a ser percorrido aconselhou inflexões de percurso e alterações nos propósitos. O clássico papel de "monitorização" e de "controlo" que caracterizava a atuação dos serviços da inspeção está a ser substituído por modalidades de apoio, como o trabalho em parceria com as escolas e a disponibilização de modelos e de ferramentas para o autoaperfeiçoamento. A tendência atual reserva à avaliação externa um papel complementar e de apoio e dá primazia à avaliação interna enquanto contributo para o desenvolvimento da escola. Trata-se, como afirmam Mcbeath e McGlym (2002), de um modelo no qual a avaliação externa se centra, antes de mais, na promoção da capacidade das escolas para se avaliarem.

Em Portugal, os processos de avaliação das escolas ainda têm uma curta história, em relação a outros países do espaço europeu. Apesar de, ao longo das duas últimas décadas, terem sido desenvolvidos diversos programas, projetos e procedimentos de avaliação externa de escolas dos Ensinos Básico e Secundário, tanto da iniciativa de instituições privadas (com destaque para a Fundação Manuel Leão, responsável pelo Programa AVES Avaliação de Escolas Secundárias), como de organismos da administração 
educativa (Inspeção-Geral da Educação e Instituto de Inovação Educacional), as medidas de política educativa no âmbito da avaliação das escolas só surgiram em 2002, com a aprovação do sistema de avaliação da educação, que compreende a avaliação externa e a avaliação interna, sendo esta última obrigatória.

A complementaridade que, como referimos anteriormente, deve caracterizar estas duas modalidades de avaliação, ainda não é uma realidade nas escolas portuguesas. Quanto à avaliação interna, que não fazia parte da cultura e das práticas das escolas portuguesas, o seu emergir, por via legal, veio lançar um desafio a que, de forma mais ou menos estruturada, as escolas têm vindo a responder.

Correspondendo ao que está disposto no documento legal, mas também a processos e a princípios em que assenta a avaliação de escolas que é realizada noutros países que nos serviram de inspiração, o projeto de avaliação externa pretende assumir-se como um contributo relevante para o desenvolvimento das escolas e para a melhoria da qualidade das aprendizagens dos alunos, numa perspetiva reflexiva e de aperfeiçoamento contínuo (IGE, 2010), sendo seus objetivos: promover o progresso das aprendizagens e dos resultados dos alunos, identificando pontos fortes e áreas prioritárias para a melhoria do trabalho das escolas; incrementar a responsabilização a todos os níveis, validando as práticas de autoavaliação das escolas; fomentar a participação na escola da comunidade educativa e da sociedade local, oferecendo um melhor conhecimento público da qualidade do trabalho das escolas; e contribuir para a regulação da educação, dotando os responsáveis pelas políticas educativas e pela administração das escolas de informação pertinente.

A avaliação externa é realizada por uma equipa constituída por três elementos: dois inspetores e um avaliador externo à IGE, na maioria docentes e investigadores do Ensino Superior, que operam com o referencial que atrás referimos. Em termos processuais, compreende três etapas, consideradas fundamentais para o conhecimento aprofundado da escola avaliada, mas também para a devolução à mesma de informação que a auxilie a implementar os necessários processos de melhoria: 1) análise de documentos disponibilizados pela escola e de dados recolhidos através de inquéritos de opinião aplicados a alunos, pais, pessoal docente e não docente; 2) visita à 
escola, com a duração de dois ou três dias consoante se trate de uma escola não agrupada ou de um agrupamento de escolas; 3) redação de um relatório da escola/agrupamento, da responsabilidade da equipa de avaliação externa, com base nas evidências recolhidas. Após o envio do relatório, a escola avaliada dispõe de um prazo para apresentar um contraditório. Os relatórios e os contraditórios são publicados na página da Internet da IGE.

O balanço do primeiro ciclo de avaliação mostra que há dois aspetos que se constituem como o cerne de todo o processo: um que tem a ver com a criação de uma cultura de avaliação de escola e com a sua interiorização pela comunidade educativa - correndo-se o risco, caso não exista, de o mesmo não vir a ter implicações significativas na melhoria real e efetiva da qualidade que é oferecida pelo estabelecimento de ensino; outro que se prende com a relação estreita que deverá existir entre a necessidade de se desenvolver essa cultura de avaliação e uma nova forma de encarar a gestão e o planeamento estratégico. A evolução que se tem vindo a observar nos modelos de gestão das organizações escolares tende a valorizar a relação de sentido entre a orientação que é dada à organização educativa - à sua missão, visão e valores que defende - e a identidade de cada escola. Neste contexto, a avaliação da escola surge como um instrumento fundamental para o seu conhecimento, caracterização e identificação dos seus problemas, assim como para a conceção de planos de ação adequados e que a escola pode desenvolver, o que, indubitavelmente, significa um determinado exercício da(s) liderança(s).

\subsection{A liderança}

A liderança das organizações escolares deve ser entendida como um meio para o desenvolvimento de uma ação educativa e pedagógica (Costa, 2000; Lima, 2002), operativamente traduzida numa gestão partilhada (Sergiovanni, 1998, 2004), cujo exercício e eficácia exigem, por um lado, efetividade e reconhecimento e, por outro, o recurso a estratégias concertadas de ação e de promoção do empenhamento individual e coletivo de toda a comunidade educativa na realização de projetos de trabalho, visando a resolução dos problemas difíceis de solucionar (Nóvoa, 1992; Fullan, 2001; English, 2008; Fontoura, 2008).

Para precisar o sentido substantivo do conceito, haverá que distinguir liderança de gestão, embora uma e outra sejam complementares no exercício 
da função de direção. Assim, enquanto a ação do gestor visa essencialmente fazer funcionar a instituição no quadro dos normativos gerais e próprios (Ruzafa, 2003), assumindo o mesmo mais uma função de controlo, através do orçamento, da planificação de atividades e de outros instrumentos de organização e regulamentação da vida da escola, a do líder deve sobretudo estabelecer metas de futuro, concitar compromissos e promover e orientar mudanças (Estêvão, 2000).

Deste modo, ao exercer a liderança, o diretor deve não apenas centrarse na atividade efetivamente desenvolvida na sua escola e promover um diálogo e um intercâmbio permanentes entre os professores, de modo a que eles problematizem as suas práticas e as circunstâncias em que as desenvolvem, visando a sua melhoria (Ruzafa, 2003), mas também apostar na oferta educativa, no desenvolvimento profissional dos professores e no desenvolvimento organizativo da escola na sua totalidade (Gairín \& Villa, 1999), num processo que, segundo Bolívar (1997), se traduz num exercício múltiplo e dinâmico da liderança. Este pressupõe um conjunto de competências de nível técnico, instrumental, de ação moral e de transformação, que se constroem pela formação e aprendizagem (Sanches, 1996; English, 2008), realiza-se em função de três tipos de variáveis (as características pessoais do líder, as estruturas da organização e a cultura de escola), e é influenciado por três dimensões: i) a legal, no quadro do estatuto legal ou formal do cargo na organização-escola; ii) a pessoal, como consequência das características pessoais do director; e iii) a funcional, que tem por referente as características do grupo e o seu grau de adequação a estas (Ciscar \& Uria, 1986, cit. por Gairín \& Villa, 1999).

$\mathrm{Na}$ verdade, o exercício da liderança das organizações escolares compreende as dimensões técnica, humana, pedagógica, simbólica, cultural e política (Gairín \& Villa, 1999) e, para que o mesmo seja eficaz, não pode descurar a dimensão moral da educação, a natureza social e interpessoal das práticas educativas, a dimensão instrucional e a natureza política da educação. Neste contexto, o diretor, continuando a ser o gestor das tarefas administrativas, assume-se como o animador da "mudança e da participação", o coordenador da ação dos diversos órgãos (Fonseca, 2000) e, principalmente, como "comunicador", que previne, gere e medeia os conflitos, promove e incentiva as boas relações entre os elementos da comunidade 
escolar e toma decisões consentâneas com os interesses e necessidades desta (Fullan, 2001).

Independentemente dos diferentes modelos que, diacronicamente, têm suportado o exercício da liderança, desde os tradicionais (mecanicistas, burocráticos, formais e hierárquicos) aos democráticos e participativos, aos políticos, aos subjetivos, aos ambíguos, aos colaborativos e colegiais, ou até mesmo aos educativos e pedagógicos (Costa, 2000; Sanches, 2000; Rocha, 2000), traduz-se o mesmo numa pluralidade de práticas, que, na nossa opinião, deverão configurar uma perspetiva "transformacional" (Burns, 1978) da escola, que se expresse em abertura às novas ideias, tolerância para com a divergência de opiniões, valorização do fracasso como fonte de aprendizagem, questionamento de suposições de base, pensamento prospetivo especulativo e procura de relações e de coerência sistemática (Glatter, 2007).

No sistema educativo português, os normativos que definem os órgãos e as áreas de intervenção das lideranças escolares configuram um modelo em que existe uma partilha de responsabilidades e em que os processos de tomada de decisão são assumidos pelo coletivo dos órgãos (Conselho Executivo/Diretor, Conselho de Escola/Conselho Geral e lideranças intermédias), o que se traduz numa descentralização interna da gestão, que se exerce e manifesta de forma dispersa, originando múltiplas lideranças que deverão funcionar de forma articulada e complementar (Ainley \& McKenzie, 2000). Prevalece, assim, um modelo de liderança baseado em princípios de colegialidade (Sanches, 2000), que possibilitam uma ação organizacional e pedagógica de reforço mútuo e facilitadora da expressão individual. Esta prática de liderança assenta, portanto, numa rotatividade de papéis, decorrente da possibilidade dos professores exercerem diferentes funções dentro da organização educativa, o que expande a sua perceção acerca da realidade e possibilitará a identificação de uma voz e de uma identidade que permitem relações de segurança e de governo partilhado, a aprendizagem a partir dos outros e com os outros e, ainda, a criação de uma cultura de colaboração, de relação e de ligação com a comunidade (Beatie, 2002; Gold, Evans, Earley, Halpin, \& Callarbone, 2003; Leithwood 1994). Como consequência lógica, a liderança deverá rentabilizar a colaboração e o compromisso para proporcionar estruturas e meios propícios ao diálogo. 
Desta forma, serão criadas condições para que as múltiplas vozes (de professores, alunos, famílias e outros agentes da comunidade), que expressam diferentes ideias, sejam ouvidas nos processos de mudança e de desenvolvimento organizacional (Ross \& Gray, 2006; Robertson, 1999).

A ação da liderança tem, portanto, de ser criativa e inovadora, e os líderes devem estar preocupados com a criação e a recriação de comunidades de aprendizagem que envolvam toda a vida democrática da comunidade educativa (Barker, 2007), pelo que é fundamental a recolha e a circulação da informação. Quanto a esta última, apesar dos condicionalismos a que está sujeita nas organizações escolares, enquanto sistemas complexos, abertos e holísticos, a difusão da informação entre os professores, sobre as várias dimensões do funcionamento organizacional da escola, estimula o próprio fluxo da informação e fomenta a mudança. Além disso, a intensidade e a qualidade da informação dependem do nível de produção de conhecimento e do grau de interação entre as estruturas, bem como da cultura de comunicação dentro do sistema (Fullan, 2001).

Em Portugal, a co-habitação, numa mesma unidade educativa, de docentes com diferentes formações e que lecionam ciclos de ensino distintos, a par da dispersão geográfica que caracteriza os agrupamentos de escolas, poderão, também, constituir-se como fatores propícios à existência de bloqueios que impedirão situações de diálogo e que dificultarão a circulação e a apropriação da informação. Trata-se de uma situação que urge ponderar, tendo presente que, como vários estudos demonstram, qualquer que seja o tipo de escola, o efetivo uso da informação mostra-se eficaz para identificar expectativas e para estimular processos de questionamento e de discussão que se traduzem em desenvolvimento (Bert \& Gerry, 2005; Coppieters, 2005). A manutenção de circuitos de circulação da informação que garanta que o conhecimento sobre a escola se estabelece é, pois, uma condição que as lideranças devem observar e garantir. Desta forma, terão as mesmas que assegurar a circulação e a qualidade da informação, bem como a variedade e a diversidade de meios e de formas através dos quais ela circula. Têm ainda que garantir a eficácia dessa circulação, através de um sistema claro de delegação de responsabilidades que garanta que o conhecimento existente sobre os indicadores de desenvolvimento, progresso e melhoria da escola é apropriado pela comunidade educativa. 


\section{Aspetos metodológicos}

Tendo por objeto de estudo a liderança das escolas portuguesas dos Ensinos Básico e Secundário, agrupadas e não agrupadas, o presente artigo apresenta, numa abordagem própria e de acordo com uma perspetiva metodológica integradora do qualitativo e do quantitativo (Shulman, 1986), dados obtidos no quadro do projeto de investigação atrás referido.

Para o efeito, considerámos os dados resultantes da análise de conteúdo, de natureza categorial (Bardin, 1979), dos 293 relatórios de avaliação externa realizados pela Inspeção-Geral da Educação, respeitantes às regiões do Algarve, Alentejo e Lisboa e Vale do Tejo, e elaborados nos anos letivos de 2006/2007, 2007/2008 e 2008/2009. Tomámos como objeto de análise, no domínio da liderança, quatro grandes categorias: i) exercício da autoridade (Conselho Executivo/Diretor 4 , Conselho de Escola/Conselho Geral e lideranças intermédias); ii) visão; iii) processos de tomada de decisão; e iv) partilha e circulação da informação, que compreendem diferentes subcategorias. Os dados das categorias foram sistematizados em quadros, constituídos pelo número de relatórios e respetivo valor percentual, por região, em que se encontram presentes as diferentes subcategorias, bem como o respetivo somatório e valor percentual relativo à totalidade dos 293 relatórios. Será com base nestes quadros que procederemos à análise interpretativa dos dados.

A opção pela análise das referidas categorias justifica o objetivo principal a que nos propusemos e que se traduz na caracterização da liderança nas três regiões consideradas e, em função da natureza desta, compreender como as organizações educativas põem em prática a sua visão de escola e como implementam a partilha e a circulação da informação para darem consecução aos seus objetivos, dando assim corpo à linha hierárquica de exercício do poder.

\section{Apresentação e discussão dos resultados}

A análise dos relatórios evidenciou uma linha hierárquica de exercício da liderança, que vamos procurar caracterizar partindo dos dados relativos à categoria 'exercício da autoridade', aos seus diversos níveis - tendo em consideração o anterior e o atual regime de administração e gestão das escolas - (Conselho Executivo/Diretor, Conselho de Escola/Conselho Geral e 
lideranças intermédias), que configura diferentes estilos de liderança, que se expressam e, ao mesmo tempo, são conformados pela 'visão' de escola a que dão corpo, pelos 'processos de tomada de decisão' que implementam e pela 'partilha e circulação da informação' que usam e fomentam nos seus agentes.

\subsection{Exercício da autoridade}

Detenhamo-nos, então, na análise interpretativa dos dados relativos ao exercício hieráquico da autoridade pelos órgãos da escola, que consubstancia a respetiva liderança.

\subsubsection{Conselho Executivo/Diretor}

Nos relatórios de avaliação externa, a liderança do Conselho Executivo/Diretor é caracterizada segundo diferentes perspetivas, de cuja análise emergiram as seguintes dimensões: estilo de liderança; definição (ou indefinição) de procedimentos; tipo de gestão (estratégica ou não estratégica); e capacidade de mobilização dos demais órgãos e da comunidade escolar (Quadro 1) - as quais passamos de imediato a analisar.

\section{Quadro 1 - Conselho Executivo, por região}

\begin{tabular}{|c|c|c|c|c|c|c|c|c|}
\hline & \multicolumn{2}{|c|}{ Algarve } & \multicolumn{2}{|c|}{ Alentejo } & \multicolumn{2}{|c|}{$\begin{array}{c}\text { Lx Vale } \\
\text { Tejo }\end{array}$} & \multicolumn{2}{|c|}{ Total } \\
\hline & $\mathbf{N}$ & $\%$ & $\mathbf{N}$ & $\%$ & $\mathbf{N}$ & $\%$ & $\mathbf{N}$ & $\%$ \\
\hline \multicolumn{9}{|l|}{ Conselho Executivo } \\
\hline \multicolumn{9}{|l|}{ Estilo de liderança } \\
\hline Ativa/Empenhada/Forte & 3 & 7,32 & 4 & 7.02 & 29 & 14,87 & 36 & 12,29 \\
\hline \multicolumn{9}{|l|}{ Abertura e disponibilidade } \\
\hline Ação educativa & 22 & 53,66 & 14 & 24.56 & 53 & 27,18 & 89 & 30,38 \\
\hline Relacional/Afetiva & 11 & 26,83 & 14 & 24.56 & 67 & 34,36 & 92 & 31,40 \\
\hline Relacional/Afetiva negativa & 1 & 2,44 & 0 & 0.00 & 2 & 1,03 & 3 & 1,02 \\
\hline Liderança centralizada & 1 & 2,44 & 2 & 3.51 & 11 & 5,64 & 14 & 4,78 \\
\hline Outros & 3 & 7,32 & 1 & 1.75 & 9 & 4,62 & 13 & 4,44 \\
\hline \multicolumn{9}{|l|}{ Definição/Indefinição de procedimentos } \\
\hline Indefinição & 4 & 9,76 & 7 & 12.28 & 50 & 25,64 & 61 & 20,82 \\
\hline Definição & 5 & 12,20 & 14 & 24.56 & 50 & 25,64 & 69 & 23,55 \\
\hline Tipo de gestão & 0 & 0,00 & 1 & 1.75 & 0 & 0,00 & 1 & 0,34 \\
\hline Gestão não estratégica & 4 & 9,76 & 10 & 17.54 & 25 & 12,82 & 39 & 13,31 \\
\hline Gestão estratégica & 9 & 21,95 & 23 & 40.35 & 65 & 33,33 & 97 & 33,11 \\
\hline \multicolumn{9}{|c|}{ Capacidade de mobilização/partilha de visão } \\
\hline Fraca capacidade de mobilização & 4 & 9,76 & 3 & 5.26 & 13 & 6,67 & 20 & 6,83 \\
\hline Partilha de visão/ação mobilizadora & 3 & 7,32 & 6 & 10.53 & 40 & 20,51 & 49 & 16,72 \\
\hline
\end{tabular}


Em termos globais, a liderança dos Conselhos Executivos/Diretores de escola, considerado o conjunto das três regiões, caracteriza-se, de acordo com os dados, pelo exercício de uma autoridade que se expressa, essencialmente: i) pela abertura e disponibilidade, traduzida na aposta numa dimensão relacional/afetiva, identificada em 92 relatórios $(31,40 \%$ do total de 293), e na ação educativa (89 relatórios, ou $30,38 \%$ ); e ii) pela implementação de um processo de gestão, que oscilará entre a definição (69 relatórios, isto é, $23,55 \%$ do seu total) e a indefinição (61 relatórios, ou 20,82\%), e cuja natureza será essencialmente estratégica (aspeto referido em 98 relatórios, que representam $33,11 \%$ do respetivo total), embora a mesma tenha sido considerada como não estratégica em 39 relatórios (13,31\%). Ainda como traços caracterizadores do exercício da autoridade pelos Conselhos Executivos/Diretores, mas com menor peso relativo, poderemos referir a partilha da visão de escola, no sentido da mobilização dos demais parceiros educativos (16,72\%, correspondentes a 49 relatórios), e o ser a mesma ativa/empenhada/forte (12,29\%).

Em termos mais específicos, poder-se-á afirmar que o exercício da liderança pelos Conselhos Executivos/Diretores é tendencialmente mais forte na região de Lisboa e Vale do Tejo, enquanto nas regiões do Alentejo e do Algarve assumirá um caráter mais difuso. Na generalidade, nas três regiões, tem o mesmo como características dominantes traduzir-se numa liderança aberta e disponível no domínio da ação educativa, alicerçar-se muito na dimensão relacional/afetiva, ser tendencialmente estratégico e mostrar alguma preocupação com a mobilização dos diferentes agentes educativos e da comunidade para uma ação concertada.

\subsubsection{Assembleia de Escola/Conselho Geral}

A análise de conteúdo dos relatórios conduziu a que o exercício da autoridade pela Assembleia de Escola/Conselho Geral fosse considerado em dois planos: 0 da relação com o Conselho Executivo/Diretor e o das funções da/o própria/o Assembleia de Escola/Conselho Geral, tendo os dados respetivos sido sistematizados no Quadro 2. 


\section{Quadro 2 - Assembleia de Escola/Conselho Geral, por região}

\begin{tabular}{lrrrrrrrc}
\hline & \multicolumn{1}{c}{ Algarve } & \multicolumn{2}{c}{ Alentejo } & \multicolumn{2}{c}{ Lx Vale Tejo } & \multicolumn{2}{c}{ Total } \\
\hline & $\mathbf{N}$ & $\%$ & $\mathbf{N}$ & $\%$ & $\mathbf{N}$ & $\%$ & $\mathbf{N}$ & $\%$ \\
\hline Assembleia de Escola/Cons. Geral & & & & & & & & \\
$\quad$ Relação com o CE & 12 & 29,27 & 4 & 7,02 & 9 & 4,62 & 25 & 8,53 \\
$\begin{array}{l}\text { Função da Ass. Escola/Cons. Geral } \\
\quad\end{array}$ & & & & & & & & \\
$\quad$ Ausente & 1 & 2,44 & 1 & 1,75 & 3 & 1,54 & 5 & 1,71 \\
$\quad$ Formal & 5 & 12,20 & 10 & 17,54 & 16 & 8,21 & 31 & 10,58 \\
$\quad$ Interventiva & 11 & 26,83 & 16 & 28,07 & 42 & 21,54 & 69 & 23,55 \\
$\quad$ Elementos & 3 & 7,32 & 0 & 0,00 & 16 & 8,21 & 19 & 6,48 \\
\hline
\end{tabular}

A referência à relação da Assembleia de Escola/Conselho Geral com o Conselho Executivo/Diretor foi apenas encontrada, para o conjunto das três regiões, em 25 relatórios (8,53\% do total de 293). Parece-nos que estes resultados traduzem algum divórcio, ou, pelo menos, uma não assumida complementaridade entre os dois órgãos de cúpula da liderança das instituições escolares.

Por outro lado, no que às funções da Assembleia de Escola/Conselho Geral diz respeito, definir-se-ão as mesmas, de acordo com o conteúdo dos relatórios analisados, sobretudo como interventivas (69 relatórios, ou 23,55\% do seu total). Não deixa, porém, de ser significativo que, de acordo 31 relatórios $(10,58 \%)$, sejam tidas como formais, e que, em função de outros 5 $(1,71 \%)$, possam ser categorizadas como ausentes. Haverá casos, ainda, em que a ação deste órgão terá como imagem a ação de alguns dos seus elementos, aspeto que se deve a 19 relatórios, que representam 6,48\% do seu total.

Genericamente, poder-se-á afirmar, como resultado da análise feita, que a participação da Assembleia de Escola/Conselho Geral no exercício da autoridade ou da liderança oscilará entre a intervenção e a formalidade. Contudo, em qualquer das três regiões cujos relatórios de avaliação externa foram objeto de análise, a função de intervenção é mais expressiva, sobrepondo-se à autoridade.

\subsubsection{Lideranças intermédias}

As lideranças intermédias são descritas, nos relatórios, nos planos da qualidade da articulação entre estruturas, das formas de participação na 
gestão escolar, do nível de reconhecimento e integração na organizaçãoescola e dos limites da sua atuação - aspetos que, na análise de conteúdo efetuada, foram globalmente considerados como definidores da "linha hierárquica" do exercício do poder no que a este nível da liderança das escolas diz respeito (Quadro 3).

Quadro 3 - Lideranças intermédias, por região

\begin{tabular}{|c|c|c|c|c|c|c|c|c|}
\hline & \multicolumn{2}{|c|}{ Algarve } & \multicolumn{2}{|c|}{ Alentejo } & $\begin{array}{c}\text { Lx Vale } \\
\text { Tejo }\end{array}$ & \multirow[b]{2}{*}{$\mathbf{N}$} & \multicolumn{2}{|r|}{ Total } \\
\hline & $\mathbf{N}$ & $\%$ & $\mathbf{N}$ & $\%$ & $\mathbf{N}$ & & & $\%$ \\
\hline \multicolumn{9}{|l|}{ Linha hierárquica/Liderança intermédia } \\
\hline \multicolumn{9}{|l|}{ Articulação entre estruturas } \\
\hline Boa articulação & 5 & 12,20 & 15 & 26,32 & 76 & 38,97 & 96 & 32,76 \\
\hline Reduzida & 2 & 4,88 & 7 & 12,28 & 9 & 4,62 & 18 & 6,14 \\
\hline Submissão ao CE & 1 & 2,44 & 0 & 0,00 & 0 & 0,00 & 1 & 0,34 \\
\hline \multicolumn{9}{|l|}{ Formas de participação } \\
\hline Gestão do serviço pedagógico & 5 & 12,20 & 3 & 5,26 & 11 & 5,64 & 19 & 6,48 \\
\hline Mobilização e corresponsabilização & 0 & 0,00 & 2 & 3,51 & 11 & 5,64 & 13 & 4,44 \\
\hline Monitorização da ação educativa & 3 & 7,32 & 2 & 3,51 & 10 & 5,13 & 15 & 5,12 \\
\hline Outras & 0 & 0,00 & 1 & 1,75 & 3 & 1,54 & 4 & 1,37 \\
\hline Reconhecimento e integração & 17 & 41,46 & 14 & 24,56 & 58 & 29,74 & 89 & 30,38 \\
\hline Limites de atuação & 14 & 34,15 & 6 & 10,53 & 40 & 20,51 & 60 & 20,48 \\
\hline
\end{tabular}

Considerando os dados em termos globais, para o conjunto das três regiões, verificamos que a articulação entre estuturas é caracterizada como 'boa' em 96 relatórios, que representam 32,76\% do total de 293, e que é o valor percentual mais elevado de todos os parâmetros que compõem esta categoria de análise. Deve notar-se, porém, que, em 18 relatórios (6,14\%), esta articulação é reputada de reduzida, o que não poderá deixar de ser levado em linha de conta. É também de assinalar que apenas em 1 relatório $(0,34 \%)$ as estruturas intermédias são tidas como em submissão ao Conselho Executivo/Diretor.

Interpretando estes dados, no seu conjunto, poder-se-ia dizer que, nas escolas e agrupamentos cujos relatórios foram analisados, as lideranças intermédias exercem a sua ação de forma relativamente autónoma e, por certo, em complementaridade com os demais órgãos das respetivas instituições. Tal interpretação parece reforçar-se quando, em 89 relatórios $(30,38 \%$ do seu total), se afirma o reconhecimento e a integração das 
estruturas intermédias no exercício da liderança, sendo, no entanto, mitigada pela constatação de que são reconhecidos limites de atuação às mesmas em 60 relatórios (20,48\%). Esta relativização parece ainda tomar mais sentido quando atentamos nos baixos valores percentuais das diferentes formas de participação das lideranças intermédias, cujos valores oscilam ente 6,48\% (19 relatórios) e 1,37\% (4 relatórios). Destas formas de participação salientem-se, no entanto, as que se referem à gestão do serviço pedagógico (19 relatórios, ou 6,48\%), a da monitorização da ação educativa (15 relatórios, isto é, 5,12\% do total de 293) e a da mobilização e corresponsabilização (13 relatórios, ou $4,44 \%)$.

Em síntese, parece poder afirmar-se que o exercício da autoridade pelas estruturas intermédias se define, principalmente - e por ordem decrescente de peso relativo dos respetivos fatores, nas regiões de Lisboa e Vale do Tejo, Alentejo e Algarve -, por uma boa articulação entre elas, embora as escolas desta última região assumam a primazia quanto ao reconhecimento e integração das lideranças intermédias, bem como dos respetivos limites de atuação, seguindo-se-lhe a região de Lisboa e Vale do Tejo e, por último, a do Alentejo. No que às formas de participação respeita, as três regiões, com algumas variações numéricas, apresentam idêntico padrão de resultados, sendo apenas de salientar a ausência de referências à mobilização e corresponsabilização das lideranças intermédias nos relatórios da região do Algarve.

\subsection{Visão}

Nos relatórios analisados, a "visão" é configurada pelos objetivos, metas e estratégias que estão definidos pela escola ou agrupamento, nomeadamente pelas áreas de intervenção prioritária e pelas estratégias utilizadas para os alcançar, na oferta educativa que é disponibilizada, considerada adequada à realidade social em que a escola se integra, e, ainda, pela visão estratégica de desenvolvimento futuro (visão prospetiva/futuro/ oportunidades) (Quadro 4). 
Quadro 4 - Visão, por região

\begin{tabular}{lcccccccc}
\hline & Algarve & Alentejo & \multicolumn{2}{c}{$\begin{array}{c}\text { Lx Vale } \\
\text { Tejo }\end{array}$} & Total \\
\hline & $\mathbf{N}$ & $\%$ & $\mathbf{N}$ & $\%$ & $\mathbf{N}$ & $\%$ & $\mathbf{N}$ & $\%$ \\
\hline Visão & & & & & & & & \\
Objetivos, metas e estratégias & & & & & & & & \\
$\quad$ Áreas de intervenção prioritária & 7 & 17,07 & 17 & 29.82 & 45 & 23,08 & 69 & 23,55 \\
$\quad$ Estratégias & 0 & 0,00 & 2 & 3.51 & 5 & 2,56 & 7 & 2,39 \\
Oferta educativa & 16 & 39,02 & 39 & 68.42 & 102 & 52,31 & 157 & 53,58 \\
Visão prospet./Futuro/Oportunid. & 4 & 9,76 & 18 & 31.58 & 63 & 32,31 & 85 & 29,01 \\
\hline
\end{tabular}

Os dados apurados para as três regiões permitem concluir que, para alcançarem os objetivos, metas e estratégias a que se propõem, as escolas apostam, preferencialmente, na identificação de áreas de intervenção prioritária. A existência de 69 relatórios que o refere, num universo de 293, é elucidativa de uma prática que parece ser usual. Contudo, e inesperadamente, só 7 relatórios, que representam a reduzida percentagem de $2,39 \%$, identificam estratégias que são implementadas e que concorrerão para alcançar os objetivos que as escolas se propuseram alcançar. Os resultados parecem sugerir que não existe uma correspondência de ação estratégica que responda, operativamente, à execução do que foi considerado como campo de intervenção prioritário. A disponibilização de uma oferta educativa diversificada configura o propósito mais ilustrativo da visão das escolas avaliadas. Em 157 dos relatórios analisados, a que corresponde um valor percentual de 53,58\%, é referida a avultada e a diversificada resposta, em termos de cursos ou de respostas educativas alternativas, que permitirão ir ao encontro de diversos públicos com distintas necessidades educativas. Quanto à visão prospetiva, são 85 os relatórios que a ela aludem (32,31\% do total analisado), o que denota alguma limitação na capacidade para perspetivar um eventual desenvolvimento e de lhe dar uma resposta adequada.

Em termos globais, poder-se-á concluir que a visão das escolas analisadas se caracteriza por uma intencionalidade que se apoia em áreas de intervenção consideradas prioritárias, se traduz, abundantemente, na disponibilização de uma oferta educativa rica e diversa, embora a referência a estratégias que as tornem viáveis seja muito escassa. Quanto à capacidade das lideranças para perspetivarem o futuro e para organizarem uma resposta 
que se the ajuste, os resultados expressam, moderadamente, essa possibilidade. $\mathrm{Na}$ análise por região, verifica-se que as diferenças são subtis e acompanham o perfil que caracteriza a globalidade dos relatórios analisados. No Algarve, no Alentejo e na região de Lisboa e Vale do Tejo, as escolas reconhecem as áreas onde devem investir, mas a intencionalidade estratégica que garanta a capitalização desse investimento é muito débil, e a enorme aposta na oferta educativa e formativa não parece decorrer de uma capacidade consciente de antecipar o futuro. Prevalece, portanto, uma dinâmica de liderança de cariz processual e não intencional.

\subsection{Processos de tomada de decisão}

No que respeita aos processos de tomada de decisão, o quadro de referência da avaliação externa solicita a recolha de evidências sobre a forma como os atores são envolvidos, bem como acerca dos processos que são mobilizados pelas estruturas de liderança para a prossecução das metas que as escolas e os agrupamentos se propuseram alcançar. Como consequência, os indicadores apurados nos relatórios remetem, sobretudo, para o envolvimento nos processos de decisão, mais especificamente para a lógica de encadeamento que transfere, sucessivamente, para níveis distintos, a responsabilidade de dar cumprimento ao que está estabelecido nos documentos estruturantes da escola ou do agrupamento.

No conjunto de perguntas ilustrativas que as equipas de avaliação externa colocam aos painéis de entrevistados, surgem questões sobre a hierarquização e a calendarização dos objetivos da escola ou agrupamento, sobre a forma como a gestão promove a articulação entre órgãos, para que seja reconhecido tanto o princípio de subsidiariedade como a valorização da complementaridade decorrente da natureza das funções e responsabilidades, e ainda sobre o incentivo que lhes é dado para que tomem decisões e para que se responsabilizem por elas. A escassez de relatórios que contemplem estes aspetos, expressa no Quadro 5 - que mostra que, num universo de 293 relatórios, somente 64 sinalizam processos de tomada de decisão $(21,84 \%$ do total) -, permite concluir que os avaliadores não encontraram muitas evidências sobre este campo de ação das lideranças. Contudo, a característica mais marcante desta categoria foi a impossibilidade de discriminar distintos ângulos de apreciação deste domínio no corpus analisado e que permitisse a criação de subcategorias. 
Quadro 5 - Processos de tomada de decisão, por região

\begin{tabular}{lcccccccc}
\hline & Algarve & Alentejo & \multicolumn{2}{c}{$\begin{array}{c}\text { Lx Vale } \\
\text { Tejo }\end{array}$} & \multicolumn{2}{c}{ Total } \\
\hline & $\mathbf{N}$ & $\%$ & $\mathbf{N}$ & $\%$ & $\mathbf{N}$ & $\%$ & $\mathbf{N}$ & $\%$ \\
\hline Processos de tomada de decisão & 5 & 12,20 & 17 & 29.82 & 42 & 21,54 & 64 & 21,84
\end{tabular}

A análise discriminativa, por região, desoculta algumas discrepâncias. Na região do Algarve, só 5 relatórios referem os processos de tomada de decisão (12,20\%); no Alentejo, o número de relatórios e a respetiva percentagem são bastante mais elevados (17 relatórios, o que corresponde a um valor percentual de 29,82\%); e, finalmente, na região de Lisboa e Vale do Tejo, foram encontradas referências a esta categoria de análise em 42 relatórios (21,54\%). Não encontramos outra justificação que explique esta desigualdade se não a opção sobre o conteúdo a inserir nos relatórios, que terá sido tomada pelas equipas de avaliação externa que intervieram nas respetivas escolas. O conteúdo dos relatórios resulta de evidências que foram recolhidas em várias fontes e existem restrições e constrangimentos na sua redação, tais como limitações de espaço, mas também inerentes ao facto de serem diferentes equipas, em cada região, que desenvolvem a avaliação externa. Estas circunstâncias terão ditado opções sobre o conteúdo a incluir nos relatórios que, no que se refere aos processos de tomada de decisão, terão contribuído para uma diferente valorização entre regiões.

\subsection{Partilha e circulação da informação}

A presente categoria refere-se à comunicação, envolvimento e reconhecimento dos atores do espaço educativo. Em termos globais, a partilha e a circulação da informação expressam-se, predominantemente, ao nível da sua circulação entre a escola e a comunidade, referida em 112 dos 293 relatórios analisados, correspondendo a 38,23\% do total, no plano interno (21 relatórios, ou 7,17\%), e noutros aspetos, nomeadamente dificuldades e fraquezas condicionantes de uma circulação da informação mais eficaz (presente em 19 relatórios, 6,48\% do respetivo total) (Quadro 6). 


\section{Quadro 6 - Partilha utilização/circulação da informação, por região}

\begin{tabular}{lccccccccc}
\hline & Algarve & Alentejo & \multicolumn{2}{c}{$\begin{array}{c}\text { Lx Vale } \\
\text { Tejo }\end{array}$} & Total \\
& & $\mathbf{N}$ & $\%$ & $\mathbf{N}$ & $\%$ & $\mathbf{N}$ & $\%$ & $\mathbf{N}$ & $\%$ \\
\hline Utilização/circulação da informação & & & & & & & & \\
Escola/comunidade & 14 & 34,15 & 24 & 42.11 & 74 & 37,95 & 112 & 38,23 \\
Comunicação interna & 7 & 17,07 & 4 & 7.02 & 10 & 5,13 & 21 & 7,17 \\
Aspetos negativos & 10 & 24,39 & 3 & 5.26 & 6 & 3,08 & 19 & 6,48 \\
\hline
\end{tabular}

Numa apreciação geral a estes resultados, surgem dois destaques que merecem alguns comentários: em primeiro lugar, a valorização que foi atribuída pela avaliação externa aos processos de comunicação de informação que as escolas estabelecem com a comunidade envolvente; e, em segundo lugar, a reduzida presença, nos relatórios, de texto que refira a circulação de informação a nível interno. Se, por um lado, é interessante e positivo saber que existe uma prática tão expressiva de articulação e de contacto entre a escola e a comunidade (embora não sejam detalhados os conteúdos, objetivos e consequências dessa passagem de informação), por outro, não era esperado que a circulação interna fosse tão pouco referida. As causas desta fragilidade, no conteúdo dos relatórios, escapam à análise efetuada, e, entre outras explicações que poderiam ser avançadas, podemos admitir que a aceitação da informalidade, que normalmente caracteriza os circuitos de passagem de informação nas escolas, banalizou a sua existência ao ponto de não Ihe ser dado relevo nos relatórios produzidos.

Outro aspeto a destacar, e que recolhe um valor expressivo nos resultados apurados, diz respeito às dificuldades e às fraquezas dos processos de circulação da informação. Neste âmbito, o que é salientado, nos relatórios, são, sobretudo, as falhas que decorrem das dificuldades dos atores na utilização dos recursos tecnológicos. Constata-se, pois, que a existência de recursos não é suficiente para que a circulação da informação se desencadeie e, neste caso, as potencialidades que a tecnologia disponibiliza não são uma garantia de que a informação que é divulgada seja apropriada pelos destinatários.

Apreciados os resultados por região, genericamente, poder-se-á afirmar que, nas três regiões, a circulação da informação que toma como destinatário a comunidade é bem conseguida, não sucedendo o mesmo com 
os processos internos. Este dado é preocupante se considerarmos que estamos em presença de organizações muito complexas, com vários patamares de decisão, correspondendo, a cada um deles, níveis distintos, mas complementares, de liderança. A fraca referência a processos que sustentam uma passagem de informação que oriente a prossecução das metas que devem ser comuns pode, em nosso entender, comprometer uma liderança que, embora seja partilhada, deve integrar-se em propósitos coletivos. Por outro lado, é sabido que a circulação de informação interna, tanto pela interação que estabelece entre os professores, como pelo fornecimento de informação acerca de problemas que podem ser comunicados (tais como o desempenho dos alunos), é essencial na promoção do sucesso escolar. A sinalização, que é comum às três regiões, de aspetos negativos que, como vimos, referem dificuldades e fraquezas condicionantes de uma circulação da informação mais eficaz, pode configurar a expressão da consciência que as escolas possuem quanto às consequências das dificuldades na partilha e na circulação de informação.

\section{Conclusão}

O artigo apresentado teve como principal objetivo analisar a visão que os relatórios de avaliação externa das escolas consideradas expressam sobre o exercício da liderança das escolas portuguesas dos Ensinos Básico e Secundário - mais propriamente, as formas como as organizações educativas põem em prática a sua visão de escola e como implementam a partilha e a circulação da informação para darem consecução a metas e propósitos que estabeleceram, dando assim corpo à linha hierárquica de exercício do poder.

Em termos globais, o modelo de liderança das escolas portuguesas tem de ser perspetivado por referência aos normativos legais em vigor, os quais, contrariando uma visão tradicional centralista de governo das escolas, preveem uma partilha de visão e objetivos, de circulação efetiva da informação, de responsabilidades e de processos de tomada de decisão, o que dá origem a lideranças múltiplas que, para serem eficazes, devem funcionar, como dizem Ainley e McKenzie (2000), de forma articulada e complementar. Este modo de operar traduz-se no que Sergiovanni (2004) 
chama de "gestão partilhada", que é exercida, em concreto, a três níveis: Conselho Executivo/Diretor; Assembleia de Escola/Conselho Geral; e lideranças intermédias. Considerando estes três níveis de exercício da liderança das escolas, e sem perdermos a sua visão de conjunto, podemos afirmar que o nosso estudo nos autoriza, em termos conclusivos, à afirmação de que o Conselho Executivo/Diretor ocupa uma posição determinante no exercício da liderança e que a sua relação com a Assembleia de Escola/Conselho Geral é reduzida. De acordo com o conteúdo dos relatórios analisados, a ação deste órgão, apesar de ser a verdadeira estrutura de cúpula e de regulação do funcionamento de uma organização educativa, é pouco expressiva. Por outro lado, ao nível das lideranças intermédias, a linha hierárquica do exercício da liderança não se configura com precisão, parecendo mesmo pouco afirmativa. Este "estilo" de liderança conduz a que a visão de escola emergente dos relatórios das três regiões consideradas se revele apostada, sobretudo, na oferta educativa e na definição de áreas de intervenção prioritária. Nas regiões do Alentejo e de Lisboa e Vale do Tejo, é igualmente evidenciada uma visão prospetiva de escola.

Constata-se, portanto, que a dimensão estratégica da implementação da visão de escola está praticamente ausente do conteúdo dos relatórios, pelo que se poderá inferir um certo sentido de gestão mais processual do que verdadeiramente prospetivo e mais reativo do que ativo. De acordo com vários autores (Estevão, 2000; Gairín \&Villa, 1999), para o desenvolvimento de uma liderança educativa e pedagógica é determinante uma visão de futuro/oportunidades da escola, cuja definição passa pela seleção de áreas de intervenção prioritária, mas que assenta, sobretudo, na promoção de estratégias concertadas de ação que convoquem o empenhamento individual e coletivo dos diferentes atores educativos no sentido do desenvolvimento organizacional da escola (Nóvoa, 1992).

Em síntese, e no que se refere à 'visão', os dados evidenciam que a liderança das escolas consideradas se expressa caracterialmente pela definição de áreas de intervenção prioritária. A esta não é alheia uma certa visão prospetiva da sua ação, que as levará, porém, a um algo tímido processo de tomada de decisões. Relativamente aos processos de tomada de decisão, o conteúdo deste campo de análise remete para a articulação entre os órgãos de gestão, para a complementaridade de funções e de 
responsabilidades e, consequentemente, para a mobilização dos órgãos de liderança para o cumprimento das metas traçadas, no sentido de alcançar o compromisso do coletivo da comunidade escolar (Glass, 2000; Leithwood, Day, Sammons, Harris, \& Hopkins, 2009). A forma incipiente como os processos de tomada de decisão são referidos nos relatórios analisados denuncia alguma desvalorização que Ihe poderá ser dada, sobretudo na capacidade de afirmação individual de cada um dos órgãos de gestão da organização escolar no âmbito das competências que lhes estão atribuídas. As referências apuradas reportam, maioritariamente, uma visão normativa, salientando processos que fidelizam as decisões que são tomadas com vista à consecução das metas e objetivos contemplados nos documentos estruturantes das escolas ou agrupamentos. Numa análise comparativa por regiões, verifica-se que o número de relatórios em que esta categoria é mais referida é no Alentejo, seguindo-se a região de Lisboa e Vale do Tejo e, por último, a região do Algarve.

No domínio da partilha e circulação da informação, expresso na relação escola/comunidade, circulação interna e aspetos negativos, a análise por regiões mostra que não há diferenças assinaláveis relativamente às duas primeiras dimensões em análise. Já no que se refere à última (aspetos negativos inibidores da circulação de informação), a região do Algarve surge como a que mais os identifica. Genericamente, os dados recolhidos nesta categoria mostram uma acentuada valorização das interações que as escolas estabelecem com a comunidade envolvente, em detrimento da circulação interna da informação. Embora se reconheça a importância daquele primeiro aspeto, a fraca alusão a processos internos de partilha e de circulação de informação não é consentânea com o espírito de permanente e eficaz processo de comunicação que deve caracterizar as lideranças (Fullan, 2001).

A concluir, e em jeito de síntese, importa salientar que os resultados a que este estudo chegou não permitem tirar conclusões que extrapolem 0 âmbito, que não deixa de ser reduzido, do conteúdo dos relatórios de avaliação externa das escolas e agrupamentos - que, de facto, são uma representação da realidade observada. O conteúdo destes relatórios resulta de evidências que foram recolhidas em várias fontes, de que se destacam as entrevistas em painel que são realizadas, e existem limitações na redação dos relatórios (sobretudo de espaço), mas também inerentes ao facto de serem 
diferentes equipas, em cada região, que desenvolvem a avaliação externa. Este conjunto de circunstâncias terá contribuído para o caráter disperso que, como referimos, caracteriza, globalmente, os relatórios analisados. Contudo, é de realçar que cada relatório, per si, encerra um conteúdo próprio, que se refere a uma escola ou agrupamento em particular, e, neste sentido, ao ser devolvido à escola, reporta a visão da avaliação externa e apresenta um balanço sobre a qualidade da educação e do ensino que aquela organização escolar proporciona, podendo contribuir para a sua melhoria.

\section{Notas}

* O presente estudo foi realizado no quadro do projeto "Sucesso escolar e perfis organizacionais: Um olhar a partir dos relatórios de avaliação externa" (FSE/CED/83489/2008), cuja equipa de investigação os autores integraram.

1 Relatórios produzidos à data do início do projeto referido na nota anterior.

2 O modelo de avaliação externa em vigor no nosso país é da responsabilidade da Inspeção-Geral da Educação (IGE). Tanto a metodologia como os processos que estão subjacentes ao modelo de avaliação externa que está a ser implementado decorreram da atividade que foi desenvolvida, em 2006, pelo então designado 'Grupo de Trabalho para a Avaliação das Escolas'. Tratou-se de uma iniciativa promovida pela Administração Central e o modelo de avaliação externa proposto e experimentado numa fase-piloto assentou em anteriores experiências nacionais, tais como o Programa de Avaliação Integrada das Escolas, desenvolvido pela IGE entre 1999 e 2002, mas também em experiências internacionais, como as metodologias propostas pela European Foundation for Quality Management (EFQM) e pelo projecto da inspeção escocesa 'How Good is Our School' (IGE, 2009). Da ação deste grupo de trabalho resultou um quadro de referência para a avaliação externa das escolas.

3 Vide nota 1.

4 A publicação do Decreto-Lei $n^{\circ} 75 / 2008$ veio substituir o "Conselho Executivo" e o "Conselho de Escola" pelas figuras de "Diretor" e "Conselho Geral". À data da redação dos relatórios em análise no presente estudo (2006/2009), ainda vigoravam, na maior parte das escolas avaliadas, as figuras do "Conselho Executivo" e do "Conselho de Escola", razão pela qual se optou por utilizar ambas as designações quando nos referimos a estes órgãos.

\section{Referências}

Afonso, N. (2000). Autonomia, avaliação, e gestão estratégica das escolas públicas. In J. A. Costa, A. N. Mendes \& A. Ventura (Orgs.), Liderança e estratégia nas organizações escolares (pp. 201-216). Aveiro: Universidade de Aveiro. 
Ainley, J., \& Mckenzie, P. (2000). School governance: Research on educational and management Issues. International Educational Journal, 1(3), 139-151.

Alaiz, V. (2004). Avaliação das escolas: Actualidade e perspectivas. Revista proFORMAR online, ed. 6, p. 8. Disponível em http://www.proformar.org/ revista/edicao_6/pag_8.htm (acesso em 18 de junho de 2010).

Azevedo, J. (Org.). (2002). Avaliação das escolas. Consensos e divergências. Porto: ASA.

Azevedo, J. M. (2007). Avaliação externa das escolas em Portugal. Conferência "As escolas face a novos desafios", Lisboa (Presidência Portuguesa da União Europeia).

Bardin, L. (1979). Análise de conteúdo (1 ${ }^{a}$ ed.). Lisboa: Edições 70.

Barker, B. (2007). The leadership paradox: Can schools leaders transform student outcomes? School Effectiveness and School Improvement, 18(1), 21-43.

Barroso, J. (2004). A autonomia das escolas: Uma ficção necessária. Revista Portuguesa de Educação, 17(2), 49-83.

Beatie, M. (2002). Educational leadership: Modelling, mentoring, making and re-making a learning community. European Journal of Teacher Education, 25(2/3), 199-221.

Bert, P. M. C., \& Gerry, J. R. (2005). Linking school effectiveness and school improvement: The background and outline of the project. School Effectiveness and School Improvement, 16(4), 359-371.

Bolívar, A. (1997). Liderazgo, mejora y centros educativos. In A. Medina (Coord.), El liderazgo en educación (pp. 25-46). Madrid: UNED.

Burns, J. M. (1978). Leadership. New York: Harper.

Coppieters, P. (2005). Turning schools into learning organizations. European Journal of Teacher Education, 28(2), 129-139.

Costa, J. A. (2000). Liderança nas organizações: Revisitando teorias organizacionais num olhar cruzado sobre as escolas. In J. A. Costa, A. N. Mendes \& A. Ventura (Orgs.), Liderança e estratégia nas organizações escolares (pp. 15-33). Aveiro: Universidade de Aveiro.

English, F. W. (2008). The art of educational leadership. Balancing performance and accountability. London: Sage.

Estêvão, C. A. V. (2000). Liderança e democracia: O público e o privado. In J. A. Costa, A. N. Mendes \& A. Ventura (Orgs.), Liderança e estratégia nas organizações escolares (pp. 35-44). Aveiro: Universidade de Aveiro.

Figari, G. (1996). Avaliar, que referencial? Porto: Porto Editora.

Fonseca, A. (2000). A liderança escolar e a comunicação relacional. In J. A. Costa, A. N. Mendes \& A. Ventura (Orgs.), Liderança e estratégia nas organizações escolares (pp. 137-151). Aveiro: Universidade de Aveiro.

Fontoura, M. (2008). Política e acção pública. Entre uma regulação centralizada e uma regulação multipolar. Revista Portuguesa de Educação, 21(2), 5-31.

Fullan, M. (2001). Leading in a culture of change. San Francisco: Jossey-Bass. 
Gairín, J., \& Villa, A. (1999). Los equipos directivos de los centros docentes. Análisis de su funcionamiento. Bilbao: Universidad de Duesto.

Glatter, R. (2007). As escolas e os sistemas de ensino perante a complexidade: Desafios organizacionais. In IGE (Org.), Actas da Conferência "As escolas face aos novos desafios". Lisboa: IGE.

Gold, A., Evans, J., Earley, P., Halpin, D., \& Callarbone, P. (2003). Principled principals? Values driven leadership: Evidence from ten case studies of "outstanding" schools leaders. Educational Management \& Administration, 31(2), 127-137.

Inspecção-Geral da Educação (IGE) (2009). Avaliação externa das escolas Referentes e instrumentos de trabalho. Lisboa: IGE.

Inspecção-Geral da Educação (IGE) (2010). Avaliação externa das escolas - Relatório 2008-2009. Lisboa: IGE.

Janssens, F. J. G., \& Van Amselsvoort, G. (2008). School self-evaluations and school inspections in Europe: An exploratory study. Studies in Educational Evaluation, 34(1) p. 15-23.

Leithwood, K. (1994). Leadership for school restructuring. Educational Administration Quarterly, 30, 495-518.

Leithwood, K., Day, C., Sammons, P., Harris, A., \& Hopkins, D. (2009). Seven strong claims about successful school leadership. National College for Leadership. Disponível em http://www.nationalcollege.org.uk/docinfo?id=17387\&filename= seven-claims-about-successful-school-leadership.pdf (acesso em 10 de junho de 2010).

Lima, L. C. (2002). Modernização, racionalização e optimização: Perspectivas neotaylorianas na organização e administração da educação. In L. C. Lima \& A, J. Afonso, Reformas da educação pública: Democratização, modernização, neoliberalismo. Porto: Edições Afrontamento.

McBeath, J. (1999). Schools must speak for themselves. The case for school selfevaluation. London: Routledge.

McBeath, J., \& McGlym, A. (2002). Self-evaluation. What's in it for schools? London: Routledge Falmer.

McNamara, G., \& O'Hara, J. (2005). Internal review and self-evaluation - The chosen route to school improvement in Irland? Studies in Educational Evaluation, 31, 267-282.

McNamara, G., \& O'Hara, J. (2008). The importance of the concept of self-evaluation in the changing landscape of education policy. Studies in Educational Evaluation, 34, 173-179.

Nóvoa, A. (1992). Para uma análise das instituições escolares. In A. Nóvoa (Coord.), As instituições escolares em análise (pp. 13-43). Lisboa: Publicações Dom Quixote/Instituto de Inovação Educacional.

Robertson, J. (1999). From managing impression to leadership perspectives. International Journal of Educational Research, 29, 359-370.

Rocha, C. (2000). Perspectivas organizacionais sobre a liderança feminina em contexto educativo. In J. A. Costa, A. N. Mendes \& A. Ventura (Orgs.), Liderança e estratégia nas organizações escolares (pp. 109-118). Aveiro: Universidade de Aveiro. 
Ross, J., \& Gray, P. (2006). Transformational leadership and teacher commitment to organizational values: The mediating effects of collective teacher efficacy. School Effectiveness and School Improvement, 17(2), 179-199.

Ruzafa, J. A. M. (2003). La dirección de centros escolares. In M. T. González (Coord.), Organizácion y gestión de centros escolares. Dimensiones y procesos (pp. 225241). Madrid: Pearson Educación, S. A.

Sá, V. (2009). A (auto)avaliação das escolas: "Virtudes" e "efeitos colaterais". Ensaio: Avaliação e políticas públicas em educação, 17(62), 87-108.

Sanches, M. F. (2000). Da natureza e possibilidades da liderança colegial nas escolas. In J. A. Costa, A. N. Mendes \& A. Ventura (Orgs.), Liderança e estratégia nas organizações escolares (pp. 45-64). Aveiro: Universidade de Aveiro.

Sanches, M. F. C. (1996). Imagens de liderança educacional: Acção tecnocrática ou acção moral e de transformação? Revista de Educação, VI(1), 13-35.

Schildkamp, K. (2007). The utilization of a self-evaluation instrument for primary education. Enschede: University of Twente.

Sergiovanni, T. J. (1998). Leadership as a pedagogy, capital development and school effectiveness. International Journal of Leadership in Education, 1(1), 37-46.

Sergiovanni, T. J. (2004). Novos caminhos para a liderança escolar. Porto: Edições ASA.

Shulman, L. S. (1986). Paradigms and research programs in the study of teaching: A contemporary perspective. In M. C. Wittrock (Ed.), Handbook of research on teaching ( $3^{\mathrm{a}}$ ed.) (pp. 3-36). New York: MacMillan Publishing Company.

Simões, G. M. J. (2007). A auto-avaliação das escolas e a regulação da acção pública em educação. Sísifo - Revista de Ciências da Educação, 04, 39-48. Disponível em http://sisifo.fpce.ul (acesso em 20 de julho de 2010).

\section{Legislação}

Lei n. ${ }^{\circ}$ 31/2002, de 20 de dezembro: aprova o sistema de avaliação da Educação e do Ensino não Superior, abrangendo a Educação Pré-Escolar e os Ensinos Básico e Secundário da educação escolar da rede pública, privada, cooperativa e solidária. 
THE LEADERSHIP OF SCHOOLS IN THREE PORTUGUESE REGIONS. A VIEW FROM EXTERNAL EVALUATION

\begin{abstract}
School leadership has significant effects on the learning, development and academic success of the pupils and on the quality of educational organisations; so, to a large extent, the effectiveness of the school depends upon the way in which leadership is carried out. It is on this basis that we undertook our study which this article reports. We aim at characterising the leadership of schools and school clusters in three Portuguese regions (Algarve, Alentejo and Lisbon and Tagus Valley), based on the analysis of the content of external evaluation reports produced by teams from the General Inspectorate of Education during the 2006/2007, 2007/2008 and 2008/2009 academic years. The goals of the study were to understand how the educational organisations put into practice their vision of school and how they implement the sharing and circulation of information seeking to achieve the established goals and purposes, thereby giving form to the hierarchical ladder for the exercising of power. By analysing the data we have been able to establish a "profile" of the leaderships in the schools and school clusters that were evaluated, although we consider that their results cannot be extrapolated, given the limits in the wording of the external evaluation reports and the fact that these reports were produced by different teams from region to region and even within the regions themselves.
\end{abstract}

Keywords

External evaluation of schools; External evaluation reports; Leadership; Exercising leadership in schools 


\section{EL LIDERAZGO DE LAS ESCUELAS EN TRES REGIONES PORTUGUESAS. UNA VISIÓN DESDE LA EVALUACIÓN EXTERNA}

\section{Resumen}

El liderazgo escolar tiene efectos significativos en el aprendizaje, desarrollo y éxito académico de los alumnos y en la calidad de las organizaciones educativas, porque de sus prácticas depende, en gran medida, la eficacia de la acción de la escuela. Teniendo estos presupuestos como referencia desarrollamos el estudio al que este artículo se refiere. En él intentamos caracterizar el liderazgo en las escuelas y agrupamientos escolares de las tres regiones portuguesas (Algarve, Alentejo y Lisboa y Valle del Tajo), basándonos en el análisis de contenido efectuado a los informes de evaluación externa producidos por los equipos de la Inspección General de Educación en los años lectivos 2006/2007, 2007/2008 y 2008/2009. El estudio tuvo como objetivo comprender cómo las organizaciones educativas ponen en práctica su visión de escuela y cómo llevan a cabo el intercambio y la circulación de la información para conseguir las metas y el propósito que establecieron, conformando así la línea jerárquica de ejercicio del poder. El análisis de los datos ahora efectuado nos permitió trazar un "perfil" de los liderazgos en las escuelas y agrupamientos escolares evaluados, aunque consideramos que los resultados no son extrapolables, dados los límites de la redacción de los informes de evaluación externa y por ser éstos efectuados por equipos diferentes dependiendo de las regiones y dentro de la misma región.

\section{Palabras-clave}

Evaluación externa de las escuelas; Informes de evaluación externa; Liderazgo; Ejercicio del liderazgo

Recebido em Maio/2011

Aceite para publicação em Abril/2012 